\title{
A Final Touch for the Environmental Engineering Students at the Onset of their Profession: Senior-Year Graduation Design Project - Case Study for 2014-2015
}

\author{
http://dx.doi.org/10.3991/ijep.v6i2.5375 \\ E. Dulekgurgen, Ö. Karahan Özgün, G. Yuksek, M.E. Pasaoglu, \\ C. Unalan, O.B. Bicer, Z. Cetinkaya, I. Isik and B.E. Oner \\ Istanbul Technical University, Maslak, Istanbul, Turkey
}

\begin{abstract}
This study reports the results of problem/designbased education offered by the Environmental Engineering Department of Istanbul Technical University (ITU) through an example of the senior-year Graduation Design Project (GDP), and the outcomes of introducing new environmental management considerations to environmental system design, and impacts of those on the senior-year Environmental Engineering undergraduate students. Overall outcomes of the study and the student entries gathered on risk assessment, uncertainty, sustainability, life-cycleassessment, and resilience issues demonstrated that inclusion of those environmental management considerations to the senior-year GDP, as well as the new and improved approaches about handling the problem/design-based education, significantly broadened the perspective of the senior-year students at the onset of their profession.
\end{abstract}

Index Terms - environmental engineering education, graduation design project, life cycle assessment, problembased learning, resilience, risk assessment, sustainability

\section{INTRODUCTION}

Founded in 1773 as the very first engineering academy of the country [1], Istanbul Technical University (ITU) is still among the leading engineering and technology universities in Turkey and at the region [2]. In tandem with the present and future needs of engineering education, ITU puts special emphasis on ensuring the educational quality and continuous improvement of the education it is offering to its students; those to be the engineers of tomorrow. Accordingly, ITU is among the world universities with the highest number of accredited undergraduate programs with its 23 engineering undergraduate programs accredited by ABET EAC (Accreditation Board for Engineering and Technology, Engineering Accreditation Commission) [3].

At ITU, we are perceiving our senior-year students as our colleagues of tomorrow and trying our best to equip them with the engineering, science and technology knowledge and tools that will be handy for those nextgeneration engineers and leaders in executing their profession, whose ultimate goal and responsibility are to contribute to the public meaningfully and efficiently and serve for a sustainable society resilient enough to face, combat, and live through the inevitable and fast changes of the modern times we are living in.

With this umbrella perspective and approach to our profession and to our prospective colleagues, and also in line with the renewed definitions and requirements of the Environmental Engineering Undergraduate curricula announced by ABET EAC [4], we have implemented couple of new modules (as of 2014-2015 Spring semester) to our senior-year Graduation Design Project (GDP) course to include considerations of risk assessment, uncertainty, sustainability, life-cycle principles, environmental impacts, project management, etc., which all serve not only for comprehensive delivery of the problem-based solution approach to our senior-year students, but also for delivering the notions, point of views, and approaches to our "today's students and tomorrow's colleagues" for developing their ability to attain a broad-ranged perspective and a "from-cradle-tograve" approach in providing their prospective services as the next-generation engineers to serve for continuum of a resilient society.

\section{APPROACH AND METHODOLOGY}

\section{A. Main Line}

Scope, structure and objectives of the "Graduation Design Project" (GDP) course were significantly altered and improved in 2009-2010 as a part of the works carried out for continuous improvement of the Environmental Engineering Undergraduate Program (EEUP) at ITU, which also helped meeting the accreditation needs outlined by the ABET EAC, by then. The course is structured around the focal educational strategy of "problem-based learning (PBL)", starting with an "openended design assignment" and combining the designbased and project-based learning strategies. In addition to sharpen and broaden the knowledge and abilities of the senior-year students in designing environmental engineering systems to provide solutions to complex reallife problems, educational objectives of the GDP course also includes stimulating the students to search for a better understanding of past and/or present knowledge and supporting them to improve their problem-solving and critical thinking skills so that they develop the ability to identify, select, link, and use previous knowledge to understand and solve new problems. Course requirements, 
such as working in teams, preparing a work breakdown with a detailed timeline and individual/collective responsibilities, preparing weekly presentations/reports for team meetings, etc., are configured to facilitate collaborative working and learning of students in constructing step-by-step solutions to complex and multiphase real-world problems, as well as to improve their communication skills. Project management requirements of the course further encourage the students to improve their time-management skills and decision-making abilities. Accordingly, the GDP course has become one of the most comprehensive and powerful PBL-oriented educational instruments of the EEUP offered by ITU upon its implementation with its improved content and structure in 2010-2011 (spring semester).

GDP is a compulsory course offered at each semester at the senior-year level. Each semester, the senior-year students (approx. 15 students at Fall and 45 students at Spring) are appointed to project teams (4-5 students on each team) and assigned to design an environmental engineering system to provide solutions to the real-life environmental problems of selected regions in Turkey. Assignments typically span over a period of 18 weeks, including submission of the final report and defense in front of the jury and audience. Scope of the assignments is not limited to providing solutions to isolated problems, e.g. designing a Biological Wastewater Treatment Plant (BioWWTP), but the projects are expected to provide integrated engineering and design solutions including, e.g. designing sewer systems, providing treatment sludge handling and management solutions, generating material recovery scenarios, etc.

Two professors and two teaching assistants are assigned to each project team to help and guide the students throughout their assignments. Each project team and their assigned faculty meet on a weekly basis to discuss the results and progress of the assignment. In addition to that, joint weekly seminars are offered to the students to deliver real-life experiences and perspectives from invited professionals having expertise on environmental system design, project management, etc.

The GDPs run by the student teams include the following project management work packages: overall framework of the project, preparatory work including information and data collection regarding the project area (e.g., population, demography, current infrastructure and public services, environmental impacts, etc.) and technical site-visits and meetings with local authorities, conceptual design, comparative evaluation of process/system alternatives, detailed design and technical drawings (of processes/units, hydraulics, architecture, piping and instrumentation), brief risk assessment, financial analyses, project management, feasibility report, final report, and oral presentation of the project in front of a jury and audience.

\section{B. Improved Approaches and New Implementations}

For 2014-2015 Spring semester, instructors of one of the GDP teams (Team-7) designed and adapted the following improved approaches and new implementations to the GDP assignment of that particular team;

- Team structuring and human-components of project management: an improved approach in execution of the course- "mentoring" instead of conventional "instructing". Also, including a junior engineer to the team to act as a senior reviewer (graduate of Class2014; the preceding year). Senior-year students had responsibilities both as members of the team structured within the boundaries of the GDP course (Team-7) and as co-founders of a virtual project management company (ARITIYOR ENvirCo.)

- New features of GDP adapted from ABET EAC (20152016 Program Criteria [4]) and further: coupling concepts and basic yet well-structured analyses of the following features to the senior-year GDP: risk assessment (RA), uncertainty, sustainability, life cycle principles, and project management. Also further including risk assessment-management (RAM), lifecycle-assessment ( $L C A)$, and resilience analysis.

- Technology selection for the main biological unit alternative of the wastewater treatment plant (WWTP) designed for the GDP assignment: detailed assessment and evaluation, process calculations, technical design and drawings, feasibility study, project management, financial analyses, RAM, uncertainty, sustainability, LCA, resilience analyses of the innovative Aerobic Granular Activated Sludge (AerGAS) Technology.

\section{The Team}

Project management team members of Team-7, who were also the co-founders and/or external contributors of the virtual company (ARITIYOR ENvirCo.), were:

- 4 senior-year EEUP students; as operational members of Team-7 and partners of the virtual company,

- 1 junior environmental engineer; as senior reviewer of Team-7 and consultant of the virtual company,

- 2 teaching assistants; as assistant instructors of Team-7 and external junior consultants of the virtual company,

- 2 professors; as mentors/facilitators of Team-7 and external senior consultants of the virtual company.

\section{OUTCOMES}

\section{A. General Overview}

ABET EAC 2015-2016 Program Criteria [4] suggest that "the curriculum must prepare graduates to design environmental engineering systems that include considerations of risk, uncertainty, sustainability, lifecycle principles, and environmental impacts; and apply advanced principles and practice relevant to the program objectives". Program criteria also prescribe that "the curriculum must prepare graduates to understand concepts of professional practice, project management, and the roles and responsibilities of public institutions and private organizations pertaining to environmental policy and regulations". In conjunction with those two important sets of program criteria, the senior-year GDP was proved to be a robust tool since the team members designed the required environmental engineering system with the following considerations:

1) Risk considerations and uncertainty: in addition to the use of safety factors and coefficients in process calculations and plant design, the team prepared additional solutions and backup plans for risks of possible earthquakes, floods, sudden and unexpected increases in pollution loads, etc.

2) Sustainability: the design was formulated to last for 30 years and the solution was selected such that the payback of the investment would be affordable so the 
operation of the facility would not be under risk due to costs, and thus the treatment system would be sustainable.

3) LCA and environmental impacts: the whole design was structured for a wastewater management solution with a cradle-to-grave approach, and the environmental impacts to water bodies, air and soil are considered in details as well.

4) Advanced principles: advanced engineering techniques and tools were considered for design and technical drawing, and in particular, an innovative BioWWT technology -namely, AerGAS [5-10]- was adopted, designed, and assessed as the main biological unit of the desired treatment facility.

In addition to those considerations, proper project management was applied by the team, i.e., preparing a work breakdown structure, scheduling, detailed planning, and describing the roles and responsibilities of the team members. In order to design the required WWT facility, the team studied related environmental policy and regulations and roles and responsibilities of the relevant public institutions. Since the setup of the GDP was prepared such that the team established a "virtual" company titled "ARITIYOR ENvirCo." and that the company would be participating in a tender with their design, they needed to consider, financial issues (reveal financing possibilities, i.e., loans, grants, etc.), cost minimization, timing, etc. which prepared each team member to the real-world professional practice.

\section{B. Highlights of Risk Assessment (RA) and Management}

Risk identification, assessment, and management carried out within the conventional boundaries of the GDP included the following parameters and aspects: (i) occupational health and safety, (ii) legal responsibilities, and (iii) financial threats. In order to run an integrated risk assessment and to put that into the perspective of realworld experiences, data on occupational accidents which occurred in Turkey in the past 5 years in operating WWTPs were collected and analyzed to identify the most frequent risk factors. Accordingly, an emergency action plan was prepared, focusing on the specific high-risk units and high-risk maintenance activities of the designed facility and also offering precautionary measures and responses in case of possible high risks. Precautionary steps outlined and imposed by the related state authorities and controlling bodies, as well as the most up-to-date national legislation, were closely followed while preparing the emergency action plan.

Financial analyses were conducted for the innovative Aerobic Granular Activated Sludge (AerGAS)-based BioWWTP in comparison to a conventional alternative (A2/O; anaerobic-anoxic-oxic). Analyses of those two were done for the entire treatment train and compared with each other in terms of main economic aspects, namely capital-, operational-, and maintenance- costs, as well as tariff values. This comparative financial evaluation not only showed that the designed AerGAS-based WWTP was more feasible, but also might be less prone to financial risks compared to the conventional alternative.

Additionally and in regard to the improved and new approaches adopted by Team-7, a second RA procedure was also executed, for the first time in Turkey, to evaluate the risks of implementing the innovative AerGAS
Technology as the treatment alternative. The very first study conducted on ethical and methodological aspects of assessing the risks of implementing the AerGAS technology in the Netherlands was used as the main guide [11]. Summary of that additional RA specific for the AerGAS-based treatment facility designed by Team-7 is given in Table I. As seen from the table, main risks with mid-to-high impact were mostly due to the innovative nature of the AerGAS technology.

TABLE I.

RISK ASSESSMENT FOR INNOVATIVE AEROBIC GRANULAR ACT1VATED SLUDGE TECHNOLOGY

\begin{tabular}{|c|c|c|c|c|c|}
\hline \multirow{2}{*}{\multicolumn{2}{|c|}{ Risks $^{\mathrm{a}}$}} & \multicolumn{4}{|c|}{ Scoring $^{\mathrm{b}}$} \\
\hline & & \multirow{2}{*}{0} & \multirow{2}{*}{1} & \multirow{2}{*}{2} & \multirow{2}{*}{3} \\
\hline$A$ & $\begin{array}{c}\text { Success/failure of this new technology and } \\
\text { effect on acceptance of innovative } \\
\text { technologies in general }\end{array}$ & & & & \\
\hline 1. & $\begin{array}{l}\text { Failure of a new technology may adversely } \\
\text { affect innovation in general }\end{array}$ & & & & $\mathrm{X}$ \\
\hline 2. & $\begin{array}{l}\text { Stricter effluent requirements complicate the } \\
\text { choice for innovative technology }\end{array}$ & & $\mathrm{X}$ & & \\
\hline$B$ & Economical risks & & & & \\
\hline 3. & $\begin{array}{l}\text { Capital costs due to construction and } \\
\text { implementation of this innovative system } \\
\text { might exceed acceptable boundaries }\end{array}$ & & & $\mathrm{x}$ & \\
\hline 4. & $\begin{array}{l}\text { Local/national market perspectives may be } \\
\text { limited due to preliminary difficulties in } \\
\text { implementation of innovative technologies }\end{array}$ & & & & $\mathrm{X}$ \\
\hline 5. & $\begin{array}{l}\text { International market interest, demand, and } \\
\text { profit return might be too low }\end{array}$ & $\mathrm{X}$ & & & \\
\hline C & Sensitivity of the treatment process & & & & \\
\hline 6. & $\begin{array}{l}\text { The system may not cope with influent } \\
\text { fluctuations (volume, composition, } \\
\text { temperature) }\end{array}$ & $\mathrm{X}$ & & & \\
\hline 7. & $\begin{array}{l}\text { Controllability of formation, maintenance, } \\
\text { structural/functional stability of AerGAS }\end{array}$ & & $\mathrm{X}$ & & \\
\hline 8. & $\begin{array}{l}\text { Operational instability due to lack of self- } \\
\text { regulation }\end{array}$ & & $\mathrm{X}$ & & \\
\hline 9. & $\begin{array}{l}\text { Expensive back-up mechanisms needed in } \\
\text { case of stopping the process due to lack of } \\
\text { robustness might increase costs }\end{array}$ & & & $\mathrm{X}$ & \\
\hline$D$ & $\begin{array}{c}\text { Lack of similar full-scale systems and possible } \\
\text { problems in up-scaling the present lab- and } \\
\text { pilot-scale applications }\end{array}$ & & & & \\
\hline 10. & $\begin{array}{l}\text { Although couple of lab-scale [12-15] and } \\
\text { one pilot-scale [16] AerGAS studies have } \\
\text { been executed in Turkey, certain factors, } \\
\text { and thus results of those studies might fail to } \\
\text { be representative }\end{array}$ & & & $\mathrm{X}$ & \\
\hline 11. & $\begin{array}{l}\text { No similar full-scale systems are present in } \\
\text { Turkey as of today, and certain factors can } \\
\text { only be assessed in full-scale }\end{array}$ & & & $\mathrm{x}$ & \\
\hline $\boldsymbol{E}$ & Meeting discharge requirements and such & & & & \\
\hline 12. & $\begin{array}{l}\text { The process fails to meet the effluent } \\
\text { discharge standards }\end{array}$ & & $\mathrm{X}$ & & \\
\hline 13. & $\begin{array}{l}\text { The system fails to meet excess sludge } \\
\text { handling requirements }\end{array}$ & $\mathrm{X}$ & & & \\
\hline $\boldsymbol{F}$ & Other Risks & & & & \\
\hline 14. & $\begin{array}{l}\text { Difficulties in sludge processing compared } \\
\text { to handling of conventional AS }\end{array}$ & & $\mathrm{X}$ & & \\
\hline 15. & $\begin{array}{l}\text { Difficulties in allocating adequately } \\
\text { qualified and competent operators, etc. }\end{array}$ & & & & $\mathrm{X}$ \\
\hline 16. & $\begin{array}{l}\text { Process calculations and technical design, } \\
\text { done for the first time in Turkey, failing to } \\
\text { represent real-world conditions }\end{array}$ & & $\mathrm{X}$ & & \\
\hline
\end{tabular}

a. Table entries were adapted (with some modifications) from Ref. [11]

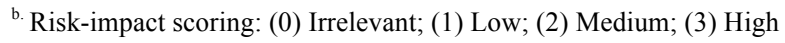




\section{Highlights of Uncertainty Analyses}

Use of certain safety factors/coefficients in process calculations and WWTP design is a common and precautionary practice which enables reaching the set effluent standards even under conditions of continuously fluctuating influent overflow rates and pollution loads [17]. On the other hand, use of inflated safety factors should be avoided to prevent overestimation of reactor volumes/footprints and overdesign of the WWTP, which eventually jeopardizes the feasibility aspect of the project.

Keeping those in perspective, a basic, simple, yet flexible design approach was preferred to run calculations of each treatment process and unit with the design parameters relevant to meet the effluent standards and to serve for the purposes that the units were meant for. Finally, designs were strictly checked against design-, average-, and peak- flow rates.

\section{Highlights of Sustainability Analyses}

When considering the economic aspects of sustainability, factors such as capital- and operational/maintenance- costs, including land requirement, number and capacity of selected mechanical equipment, as well as choice of treatment technology have important impacts on providing sustainable solutions and operation. By preferring the innovative AerGAS technology, significant energy savings were achieved in operation: AerGAS-based treatment alternative was determined to consume $24 \%$ less energy than that required by the conventional A2/O-based alternative. Accordingly, overall operational costs of the AerGAS-based facility were calculated to be $84 \%$ of the conventional one.

In addition to those savings related with energy and operational costs, selected AerGAS technology had significant advantages in terms of land requirement: due to excellently settling compact structure of granular sludge enabling installation of reactors with smaller footprints, as well as the choice of SBR (sequencing batch reactor) configuration, together eliminating the need for separate secondary clarifiers in a conventional sense, it became possible to accommodate the entire treatment train on a land $60 \%$ smaller than that required by the conventional system. This created an opportunity to reclaim the unused area for recreational activities which was assumed to help lessen possible social resistance and negative response to the treatment plant and mitigate presumed negative impacts on the local community.

Reduced energy consumption resulting in less indirect atmospheric $\mathrm{CO}_{2}$ emissions was another advantage of the designed treatment facility pursuing public health aspects and further contributing to sustainability.

\section{E. Highlights of Life Cycle Assessment (LCA)}

Life Cycle Assessment (LCA) is a tool to evaluate the total environmental impact of treatment facilities and to understand how to avoid shifting environmental impacts from one place to another [18]. For the GDP presented herein, LCA was conducted by following the framework and complying with the standards set in the ISO 14040:2006 standard [19], and four steps listed below were followed as phases of LCA:

1) Definition of scope and goal: main objective was to select a proper and representative system boundary, which was determinative for the scope and extent of the
LCA. Considering the ISO standard and examining the works presented in the literature on WWTP LCA [20], it was decided to exclude the impacts due to construction activities and focus on 30-years operational period.

2) Inventory analysis: plentiful data were available to complete a thorough inventory analysis since process calculations, system design and equipment selection were all carried out by Team-7. Hence, obtaining data was not the limiting factor, as usually encountered in LCA practices, but it was required to check the reliability of the available data against actual indicators from similar treatment plants. To achieve that, energy requirement data from currently operating full-scale AerGAS WWTPs were gathered and compared with those of the designed treatment facility. Detailed flowchart of the resulting LCA-inventory analyses with inputs and outputs in and out of each treatment unit of the AerGAS-based BioWWTP designed by Team-7 is given in Fig. 1 .

3) Life cycle impact analysis: according to the ISO 14040:2006 standard, it was required to determine the impact categories before starting to calculate and assess the important impact factors. Considering the publically accessible tools and software, it was decided to focus on the simple yet representative "Global Warming Potential $(G W P)$ " as the major impact category to assess using one of the publically accessible tools (namely, the CML Baseline methodology).

4) Interpretation: in addition to nitrogen $(\mathrm{N})$, phosphorus (P) and organic carbon (C) emissions to the aquatic environment due to discharge of treated water to the receiving water body (Melen Creek, Duzce Province, Turkey), indirect atmospheric inorganic $\mathrm{C}$ and $\mathrm{N}$ emissions $\left(\mathrm{CO}_{2}\right.$ equivalence $)$ from the designed treatment facility (Fig. 1), were also calculated to estimate the GWP of the system within the framework of LCA. As stated previously, energy consumption of the AerGAS-based WWTP was less than that of the conventional alternative. Accordingly, LCA analyses showed that the $\mathrm{CO}_{2}$ emissions of the designed system were also lower than those of the conventional one (data not shown). For the designed system, almost $50 \%$ of the total $\mathrm{CO}_{2}$ emissions (of which nearly $7 \%$ was from $\mathrm{N}_{2} \mathrm{O}$ in $\mathrm{CO}_{2}$ equivalence) was due to pumping, whereas the biological unit had a lesser share in the GWP of the system.

\section{F. Highlights of Resilience Analyses}

Resilience is defined as "capacity of a system to absorb disturbance and reorganize while undergoing change so as to still retain essentially the same function" [21], or "ability of an individual, a household, a community, a country or a region to withstand, cope, adapt, and quickly recover from stresses and shocks such as violence, conflict, drought and other natural disasters without compromising long-term development" [22].

In order to align with those definitions and concepts, a "resilience analysis" beyond the aim and scope of a conventional risk management was conducted. Considering the interrelations between resiliency and sustainability, and that sustainability of civil structures meant to span generations, heavily depends on resiliency of operation; basic but important precautionary actions were planned mainly considering the threats due to earthquakes and floods. 


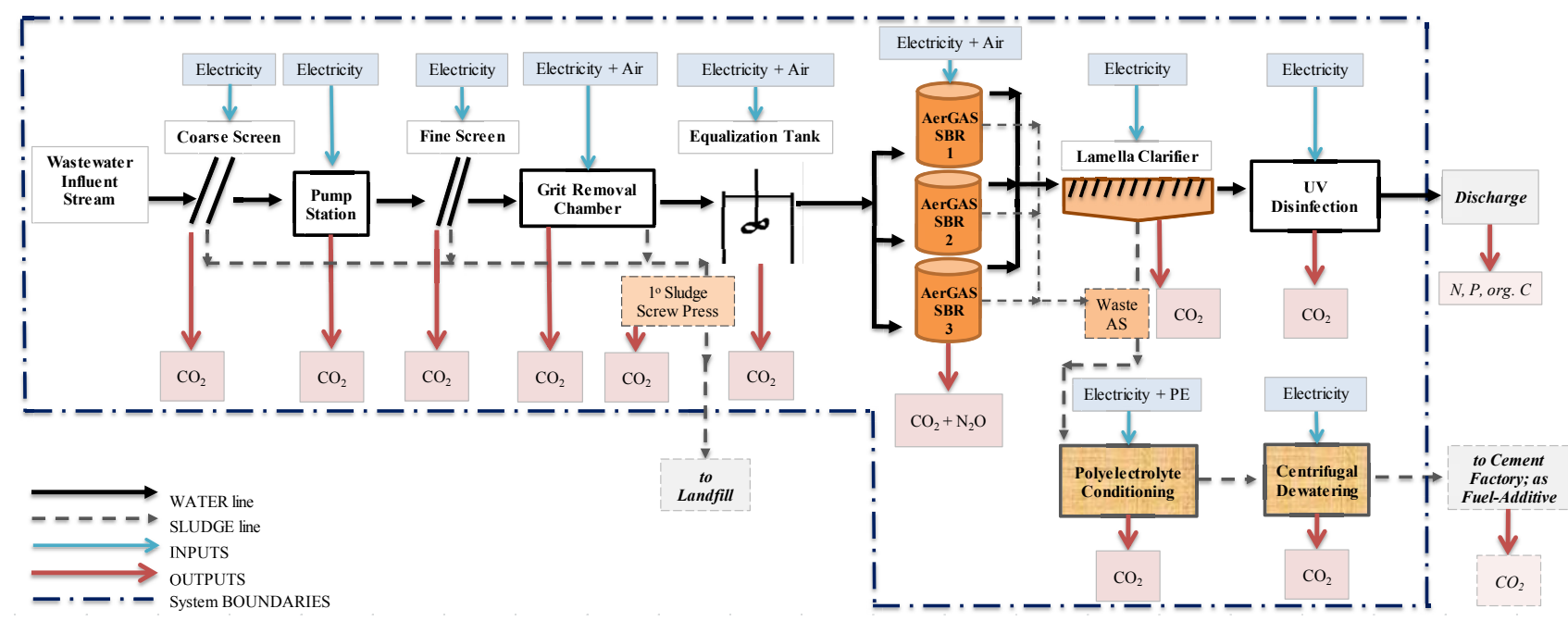

Figure 1. Life cycle assessment (LCA): inventory analysis for the AerGAS-based BioWWTP designed for Duzce Province- Marmara Region, Turkey.

Following the guidelines issued by the Environmental Protection Agency-EPA [23], mitigation measures including 6 basic prevention aspects were determined, i.e., protecting sensitive equipment such as pumps and blowers from floods by building barriers and blocks, etc. The most important element was determined as the emergency backup generators and back-up reserves, which were crucial in terms of independent operation during times of crisis and natural disaster.

Interdependency, which was presumed as one of the critical aspects of resiliency, was also included in assessment and planning by considering dependencies to other infrastructure systems. While outlining the resiliency plan, it was considered that even though the treatment facility was designed such that it would be compatible with earthquakes or floods, the recovery period would heavily depend on the conditions of other infrastructures (e.g., transportation corridors, energy infrastructure, supply chains, etc. [24]).

\section{CONCLUSIONS AND RECOMMENDATIONS}

Inclusion of the new environmental management considerations in the Graduation Design Project, as well as adapting new/improved approaches while executing the problem/design-based education have significantly broadened the perspective of our senior-year students as obvious from their following comments on risk concepts, risk assessment/management, uncertainty, sustainability, life-cycle-assessment, and resilience:

- "Risk management is inevitable for sustainable engineering systems. Identification, assessment, and evaluation of natural and/or man-made risks and hazards must be among the priorities of a sustainable engineering perspective."

- "Sustainability defined as "meeting todays' demands without compromising the needs of next generations" is not only an issue about the management of energy resources, but also should be the motto for existence and coherence of the civil works and services contributing to the prosperity and resilience of the public, as well as to preservation, protection, and remediation of the environment."
- "Putting each and every step taken during this project primarily into the "sustainability" perspective not only positively influenced the entire design- and decision making- phases, but also enabled us to get one step closer to today's real-world standards in environmental problem solving."

- "Preparedness embodied in "risk analyses and management" will ensure the fulfillment of the realworld expectations and needs by the projects and services. It will also provide the chance to establish a sustainable operational practice."

- "Risk management should be included in environmental education in a cause-and-effect context. Multidisciplinary approaches should be used in risk assessment."

- "Taking risks does not always mean bravery; rather it might be a sign of illiteracy. Hence, backup plans are always necessary."

- "Risk management should be done by an engineering approach based on scientific facts, technical analyses and calculations beyond assumptions and probabilities."

- "Understanding the principles and purpose of "lifecycle assessment (LCA)" was one of the most important gains from this project, as it is recognized as a valuable tool to be used frequently and effectively in Environmental Engineering profession."

- "LCA is a powerful tool for understanding material and energy cycles. Besides, it clearly demonstrates that transferring pollution from one location/medium to another does not provide a sustainable and integrated Environmental Engineering solution."

- "Resilience was an important new consideration in environmental management, which broadened our vision by requiring us to consider the interdependencies of the designed treatment plant to other civil infrastructures in case of natural disasters, and such."

- "Resilience is presumed as a critical new aspect of environmental management. Consideration and assessment of resiliency is prone to help create flexible and robust solutions in all engineering disciplines." 


\section{ACKNOWLEDGMENT}

This study was supported in part by the ITU CE3; Istanbul Technical University - Center for Excellence in Engineering Education.

\section{REFERENCES}

[1] ITU main web-page, Istanbul Technical University - History, http://www.itu.edu.tr/en/about-itu/general/history.

[2] Times Higher Education - THE World University Rankings; 2014 2015. http://www.timeshighereducation.co.uk/world-universityrankings/2014-15/world-ranking.

[3] ABET main web-page, http://www.abet.org/ and ABET Accredited Program Search web-page; http://main.abet.org/aps/Ac creditedprogramsearch.aspx.

[4] ABET EAC, "2015-2016 Criteria for accrediting engineering programs, Program criteria for environmental and similarly named engineering programs," in ABET EAC Criteria for accrediting engineering programs, ABET, Baltimore, MD, USA, 2014, pp. 1213. http://www.abet.org/wp-content/uploads/2015/05/E001-15-16EAC-Criteria-03-10-15.pdf.

[5] M.K. de Kreuk and L.M.M. de Bruin, "Design and economics of a full-scale GSBR treatment plant," in Aerobic Granular Reactor Technology, Water and Wastewater Practitioner Series: STOWA Report, London: IWA Publishing, 2004, pp. 24-37 and Appendices 1-7.

[6] A. Giesen, R. Niermans and M.C.M. van Loosdrecht, "Aerobic granular biomass: the new standard for domestic and industrial wastewater treatment?" Water21-April 2012, Magazine of the Int. Water Assoc., London: IWA Publishing, 2012, pp. 28-30.

[7] P. Inocencio, F. Coelho, M.C.M. van Loosdrecht and A. Giesen, "The future of sewage treatment: Nereda technology exceeds high expectations," in: Water21-April 2013, Magazine of the Int. Water Assoc., London: IWA Publishing, 2013, pp. 28-29.

[8] M.C.M. van Loosdrecht and D. Brdjanovic, "Anticipating the Next Century of Wastewater Treatment: Advances in Activated Sludge Sewage Treatment Can Improve Its Energy Use and Resource Recovery," Science, vol. 344, pp. 1452-1453, 2014. http://dx.doi.org/10.1126/science. 1255183

[9] S. Robertson, H. van de Roest and A. van Bentem, "Achieving sustainable wastewater treatment through innovation: an update on the Nereda technology," Water21-April 2015, Magazine of the Int. Water Assoc., London: IWA Publishing, 2015, pp. 39-41.

[10] A. C. van Haandel and J. G. M. van der Lubbe, "Appendix 9 Aerobic granulated sludge" in Handbook of Biological Wastewater Treatment: Design and Optimisation of Activated Sludge Systems, $2^{\text {nd }}$ ed. London: IWA Publishing, July 2012, pp.754-770

[11] S.D. van de Poel, S.D. Zwart, M. Brumsen and H.G.J. van Mil, "Risks of aerobic granular sludge technology; ethical and methodological aspects," in Aerobic Granular Sludge, S. Bathe, M.K. de Kreuk, B. McSwain and N. Schwarzenbeck, Eds. Water and Environmental Management Series, London: IWA Publishing, 2005, pp. 143-154.

[12] E. Dulekgurgen, "Hydraulic- and/or metabolic selection-pressures influenced aerobic granulation and its application in Enhanced Biological Phosphorus Removal (EBPR)", PhD dissertation, Istanbul Technical University, Institute of Sci\&Technol, Environ Engr Grad Program, 2006.

[13] TUBITAK Project 107Y137, "Investigation of structure and stability of aerobic granular sludge," Coordinator: G. Y1lmaz, 2007-2010.

[14] TUBITAK Project 108Y313, "A new approach in industrial wastewater treatment: aerobic granular biomass technology," Coordinator: E. Dulekgurgen, 2009-2012.

[15] TUBITAK Project 111Y176, "The investigation of aerobic granulation and its use for nitrogen removal in sequencing batch reactors," Coordinator: T.H. Erguder, 2011-2012.

[16] TUBITAK Project 111Y036, "On-site treatment of domestic wastewater using aerobic granular sludge technology", Coordinator: G. Y1lmaz, 2012-2015.

[17] E. Belia, Y. Amerlinck, L. Benedetti, B. Johnson, G. Sin, P. A. Vanrolleghem, K. V. Gernaey, S. Gillot, M. B. Neumann, L.
Rieger, A. Shaw and K. Villez, "Wastewater Treatment Modelling: Dealing with Uncertainties," Water Sci. Technol., vol. 60(8), pp. 1929-1941, 2009. http://dx.doi.org/10.2166/wst.2009 .225

[18] Scientific Applications International Corporation, "Life cycle assessment: principles and practice," Cincinnati, Ohio: Environmental Protection Agency, 2006, p. 3. http://www.epa.gov/nrmrl/std/lca/lca.html.

[19] ISO 14040:2006, "environmental management - life cycle assessment - principles and framework," Geneva: International Standardization Organization, 2006, http://www.iso.org/iso/cata logue detail?csnumber $=37456$.

[20] L. Corominas, J. Foley, J.S. Guest, A. Hospido, H.F. Larsen, S. Morera and A. Shaw, "Review: Life Cycle Assessment Applied to Wastewater Treatment: State of the Art," Water Res., vol. 47(15), pp. 5480-5492, 2013. http://dx.doi.org/10.1016/j.watres.2013. 06.049

[21] B. Walker, C. S. Holling, S. R. Carpenter and A Kinzig, "Resilience, Adaptability and Transformability in SocialEcological Systems, Ecology and Society," Ecology and Society, vol. 9(2), article-5, 2004.

[22] EU Factsheet-Resilience, "Building Resilience: The EU's Approach," European Commission, Brussels: Humanitarian aid and civil protection development\&cooperation -EuropeAid, 2015, p. 2, www.bit.ly/echo-fs.

[23] EPA 817-B-14 -006, "Flood Resilience: A Basic Guide for Water and Wastewater Utilities," EPA- Office of Water (4608T), USA, September 2014, p. 25, http://water.epa.gov/infrastructure/water security/emerplan/upload/epa817b14006.pdf.

[24] Oregon Government, "Water and Wastewater Systems," in The Oregon Resilience Plan - February 2013, Oregon, USA, p. 228. http://www.oregon.gov/OMD/OEM/osspac/docs/08 ORP Water. pdf

\section{AUTHORS}

E. Dulekgurgen is with the Environmental Engineering Department, Istanbul Technical University, Maslak 34467, Istanbul, Turkey. She is also the Associate Dean (Educational Quality and Accreditation) at the Office of Dean of Students (ODoS) and board member of the Center for Excellence in Engineering Education (ITU CE3), Istanbul Technical University, Maslak 34467, Istanbul, Turkey (e-mail: dulekgurgen@itu.edu.tr).

Ö. Karahan Özgün is with the Environmental Engineering Department, Istanbul Technical University, Maslak 34467, Istanbul, Turkey (e-mail: ozlem.karahan@itu.edu.tr).

G. Yuksek is a guest researcher at the Universite de Sherbrooke, Faculté de Genie, poste 65457, Quebec, Canada, on leave from the Environmental Engineering Department, Istanbul Technical University, Maslak 34467, Istanbul, Turkey (e-mail: Gulten.Yuksek@USherbrooke.ca,gulyuksek@itu.edu.tr,).

M.E. Pasaoglu is with the Environmental Engineering Department, Istanbul Technical University (ITU) and he is a researcher at the Turkish National Research Center on Membrane Technologies (MEM-TEK), ITU, Maslak 34467, Istanbul, Turkey (e-mail: mpasaoglu@itu.edu.tr).

C. Unalan was awarded the degree of BSc in Environmental Engineering in 2014 (ITU-Istanbul Technical University). He served as the external senior reviewer of a student-team executing Graduation Design Project in 2015 (ITU). He is now a graduate student Environmental Science and Engineering Graduate Program (MSc level)- at the Graduate School of Science, Engineering and Technology, Istanbul Technical University, Maslak 34467, Istanbul, Turkey (e-mail: unalan@itu.edu.tr). 
O.B. Bicer was awarded the degree of BSc in Environmental Engineering in 2015 (Istanbul Technical University). He is now working at the private sector as an occupational health and safety specialist, Osmangazi, Bursa, Turkey. He is also a graduate student Occupational Health and Safety Graduate Program (MSc level)- at the Graduate School of Science and Technology, Işık University, Osmangazi 16160, Bursa, Turkey (bugrahanbicer91@gmail.com).

Z. Cetinkaya was awarded the degree of BSc in Environmental Engineering in 2015 (Istanbul Technical University). She is now a graduate student -Environmental Science and Engineering Graduate Program (MSc level)at the Graduate School of Science, Engineering and Technology, Istanbul Technical University, Maslak 34467, Istanbul, Turkey (e-mail: cetinkayaz@itu.edu.tr).

I. Isik was awarded the degree of BSc in Environmental Engineering in 2015 (Istanbul Technical
University). He is now a graduate student -Environmental Science and Engineering Graduate Program (MSc level)at the Graduate School of Science, Engineering and Technology, Istanbul Technical University, Maslak 34467, Istanbul, Turkey (e-mail: isiki@itu.edu.tr).

B.E. Oner was awarded the degree of BSc in Environmental Engineering in 2015 (Istanbul Technical University). She is now a graduate student -Environmental Science and Engineering Graduate Program (MSc level)at the Graduate School of Science, Engineering and Technology, Istanbul Technical University, Maslak 34467, Istanbul, Turkey (e-mail: onerbu@itu.edu.tr).

This study was supported in part by the ITU CE3; Istanbul Technical University - Center for Excellence in Engineering Education. This article is an extended and modified version of a paper presented at the International Conference on Interactive Collaborative Learning (ICL2015), held 20-24 December 2015, in Florence, Italy. Submitted 15 December 2015. Published as resubmitted by the authors 13 March 2016. 